\title{
Discutindo o Gênero, Sexualidade e as Diversidades na Infância através do PNAIC
}

\author{
Discutinando el género, sesualidad y las diversidades en la Infancia \\ através del PNAIC
}

Discussing gender, sexuality and diversities in chindren thouch the PNAIC

\begin{abstract}
Ariana Souza Cavalheiro 1
Resumo

Esta pesquisa teve como objetivo analisar se/como as discussões sobre os gêneros e as sexualidades foram apresentadas dentro do Programa Pacto Nacional pela Alfabetização na Idade Certa - PNAIC. Programa destinado à alfabetização das crianças a partir de seis anos e, também, à formação continuada de professoras/es alfabetizadoras/es, que atuam nas turmas de $1^{\circ}, 2^{\circ}$ e $3^{\circ}$ anos do Ensino Fundamental, constituindo o "Ciclo de Alfabetização". A proposta, foi investigar nos materiais: Manual do PNAIC, o Material de Formação de Professores/as e as obras de literatura infantil do Acervo Complementar, as possibilidades que permitem discutir temas relacionados aos gêneros e as sexualidades, no espaço da sala de aula. Como metodologia, foi utilizada a pesquisa documental contemplando a seleção dos artefatos. Para análise e discussão dos dados, foi utilizado a Análise Cultural, a qual permitiu abordar e apresentar a cultura como uma produção social delineada pelas transformações contemporâneas, além de entender os materiais do PNAIC como artefatos culturais. Buscou-se dialogar com autoras/es como Hall, Silva, Louro, Scott, Veiga-Neto, entre outros, os quais permitem aprofundar os conceitos embasados no pós-estruturalismo e possibilitam pensar e refletir sobre feminilidades, masculinidades, artefatos culturais, pedagogias culturais, gêneros, sexualidades e infâncias. Entendendo o quanto estes artefatos são emergentes no que tange as problemáticas sobre como se (re)produzem e veiculam representações de gênero e sexualidade na atual sociedade e formação de professores/as.
\end{abstract}

Palavra-Chave: Artefatos Culturais; Infâncias; Gênero; PNAIC; Sexualidade.

\section{Resumen}

Esta investigación tuvo como objetivo analizar si / como las discusiones sobre los géneros y las sexualidades fueron presentadas dentro del Programa Pacto Nacional por la Alfabetización en la Edad Cuna - PNAIC. Programa para la alfabetización de los niños a partir de seis años y, también, a la formación continuada de profesoras / es alfabetizadoras / es, que actúan en las clases de $1^{\circ}, 2^{\circ}$ y $3^{\circ}$ años de la Enseñanza Fundamental, constituyendo el "Ciclo de Alfabetización". La propuesta, fue investigar en los materiales: Manual del PNAIC, el Material de Formación de Profesores / as y las obras de literatura infantil del Acervo Complementario, las posibilidades que permiten discutir temas relacionados a los géneros y las sexualidades, en el espacio del aula. Como metodología, se utilizó la investigación documental contemplando la selección de los artefactos. Para el análisis y discusión de los datos, se utilizó el Análisis Cultural, que permitió abordar y presentar la cultura como una producción social delineada por las transformaciones contemporáneas, además de entender los materiales del PNAIC como artefactos culturales. Se buscó dialogar con autoras / es como Hall, Silva, Louro, Scott, VeigaNeto, entre otros, los cuales permiten profundizar los conceptos basados en el post-estructuralismo y posibilitar pensar y reflexionar sobre feminidades, masculinidades, artefactos culturales, pedagogías culturales, géneros, sexualidades e infancias. Entendiendo cuánto estos artefactos son emergentes en lo que se refiere a las problemáticas sobre cómo se (re) producen y vehiculan representaciones de género y sexualidad en la actual sociedad y formación de profesores / as.

Palabra clave: Artefactos Culturales; infancia; género; PNAIC; La sexualidad.

\footnotetext{
${ }^{1}$ Pedagogia Licenciatura, Especialista em Educação Física Escolar e Mestre em Educação, pela Universidade Federal do Rio Grande - FURG. Rio Grande/ RS - Brasil. Coordenadora.arianacavalheiro@gmail.com
} 


\begin{abstract}
This research aimed to assess whether/how the discussions about genders and Sexualities were presented within the national compact for the Literacy Programme the right age-PNAIC. Program for the literacy of children from six years and, also, the continuous formation of teachers/es alfabetizadoras/s, working in groups of 1, 2 and 3 years of elementary school, constituting the "cycle of Literacy ". The proposal was to investigate the materials: PNAIC Manual, the training Material Tutors and the works of children's literature of the Complement, the possibilities that allow you to discuss topics related to genres and sexualities, within the classroom. As methodology was used documentary research contemplating the selection of artifacts. For analysis and discussion of the data, we used the Cultural analysis, which allowed address and present culture as a social production outlined by contemporary transformations, as well as understand the PNAIC materials as cultural artifacts. Sought to dialoguing with authors/es as Hall, Scott, blonde, Scott, Veiga-Neto, among others, which allow to deepen the concepts based on post-structuralism and allow you to think and reflect on feminilidades, masculinities, cultural artifacts, cultural pedagogy, genres, Sexualities and childhoods. Understanding how These artifacts are emerging regarding the problems on how to (re) produce and convey representations of gender and sexuality in modern society and training of teachers.
\end{abstract}

Keyword: Cultural Artifacts; Childhoods; Genus; PNAIC; Sexuality.

\title{
1. O "Pacto" com o referencial teórico: trilhando os caminhos da pesquisa nas contribuições dos estudos culturais
}

Ao problematizarmos as discussões de diversidade sexual e de gênero presentes no PNAIC, é necessário dar ênfase nessas discussões dentro do espaço da escola por ser um lugar primordial e importante na construção dos sujeitos, pois é nesse espaço que transitam diferentes identidades, culturas, gêneros e sexualidades. Entretanto, ainda há uma resistência ao se falar em sexualidade, provocando uma invisibilidade de temas e acontecimentos que são ocultados. Sobre essa resistência, é possível refletir a partir das palavras de Louro (2005, p. 87) ao dizer que,

em sua materialidade física, o prédio escolar informa a todos/as sua razão de existir. Servindo-se de recursos materiais, de símbolos e de códigos, a escola delimita espaços, afirma o que cada um/a pode ou não pode fazer, separa e institui. Para aqueles e aquelas que são admitidos no seu interior, a escola determina usos diversos do tempo e do espaço, consagra a fala ou silêncio.

Buscamos a partir dessa reflexão ressaltar o quanto é emergente proporcionar discussões que mobilizem as temáticas das sexualidades e dos gêneros dentro do espaço escolar, desnaturalizando padrões de comportamentos e verdades que se instituem a partir dos modos de viver e definir os corpos, gêneros e as sexualidades. Ainda hoje, é possível acompanhar um processo que se dá "através de um aprendizado eficaz, contínuo e sutil, a instituição imprime um ritmo, uma disposição física, uma postura nos sujeitos. Meninos, meninas, jovens, mulheres e homens aprendem e incorporam gestos, movimentos" (Ibid., 2005, p. 87). Assim, acabam por perceber outras possibilidades de viver suas sexualidades e seus gêneros. 
Diante do exposto, visamos promover estas discussões nesta Dissertação a partir do campo teórico dos Estudos Culturais e de Gênero, em suas vertentes pós-estruturalistas, as quais nos permitem entender as práticas culturais como produtoras de significados, e os corpos, gêneros e sexualidades como construções sociais.

Assim, iniciamos a fundamentar e (re)construir nossos entendimentos acerca das temáticas em questão, a partir da contextualização do campo teórico dos Estudos Culturais.

Os Estudos Culturais tiveram sua origem na Inglaterra, no final dos anos 1950, centrados nos estudos de Richard Hoggart (1957), Raymond Wilhiams (1958) e Edward Palmer Thompson (1963), que, por meio de seus textos, buscaram problematizar as questões relativas à cultura e ao contexto histórico da sociedade inglesa. $\mathrm{O}$ campo dos Estudos Culturais surge através do Center for Contemporary Cultural Studies (CCCS), (ESCOSTEGUY, 2001).

Os Estudos Culturais configuram-se como sendo anti/interdisciplinar, não se restringindo apenas a uma disciplina, mas sim se utilizando de um conjunto de disciplinas para estudar os processos de produção cultural. É possível entender, a partir de Turner (1990 apud ESCOSTEGUY, 2001, p. 28), que os Estudos Culturais se denominam "um campo interdisciplinar onde certas preocupações e métodos convergem; a utilidade dessa convergência é que ela nos propicia entender fenômenos e relações que não são acessíveis através das disciplinas existentes”. Segundo Colin Sparks (1997 apud COSTA, 2004, p. 14 [Tradução da Autora]):

É extremamente difícil definir os "Estudos Culturais" com qualquer grau de exatidão. Não é possível fazer demarcações e dizer que esta ou aquela seja sua esfera de atuação. Tampouco é possível indicar uma teoria ou metodologia unificada que seja característica deles ou para eles. Um verdadeiro amontoado de ideias, métodos e temáticas da crítica literária, da sociologia, da história, dos estudos da mídia, etc. São reunidos sob o rótulo conveniente de estudos culturais.

Desde sua formação, os Estudos Culturais tencionam-se a problematizar as distinções existentes entre a alta-cultura, que se constituía pelo cinema, pintura, clássicos da música e literatura, e a baixa-cultura, constituída por programas de televisão, música popular, publicidade e atividades de lazer. Essas distinções por muito tempo fizeram valer uma discussão pautada nas relações de poder (MAGALHÃES, 2008).

Para Williams (1958 apud SILVA, 2013) a cultura deveria ser entendida como o modo de vida global de uma sociedade, a experiência vivida de qualquer agrupamento humano. Sobre a cultura, Silva (2013, p. 133-134) nos diz que 
[...] é um campo de produção de significados no qual os diferentes grupos sociais, situados em posições diferentes de poder, lutam pela imposição de seus significados à sociedade mais ampla. A cultura é, nessa concepção, um campo contestado de significados.

Percebe-se, assim, que se trata de considerar a cultura em sentido amplo, antropológico, de passar de uma reflexão centrada sobre o vínculo cultura-nação para uma abordagem da cultura dos grupos sociais (MATTELART, 2004, p. 13-14). Passa, assim, a constituir-se por uma rede de representações agregadas por cada modo de vida de grupos sociais, em que se "define não apenas a forma que o mundo deve ter, mas também a forma como as pessoas e os grupos devem ser" (SILVA, 2013, p. 134).

Para os Estudos Culturais, a cultura é concebida como um campo de luta em torno da significação social (Ibid. 2013, p. 133). É possível entende-la como um campo que produz significados, pois está constituída por diferentes grupos sociais em suas diferentes representações e relações de poder.

Para Hall (2014), a cultura é apresentada como um "discurso - um modo de construir sentidos que influencia e organiza tanto nossas ações quanto a concepção que temos de nós mesmo" (p.31). Sendo a cultura uma soma de diferentes representações e símbolos sociais, como afirma Giroux (2003, p. 155),

a cultura é o terreno da contestação e da acomodação, assim como o local onde os jovens e outras pessoas imaginam sua relação com o mundo; ela produz as narrativas, as metáforas e as imagens para construir e exercer uma poderosa força pedagógica sobre a maneira como as pessoas pensam a respeito de si mesmas e de relacionamento com os outros.

Os Estudos Culturais, ao entenderem as práticas culturais como produtoras de significados, "contribuem para a desconstrução de alguns binarismos, algumas verdades que são instituídas pela sociedade e também as questões ligadas ao gênero, masculino/feminino" (Ibid., 2003, p. 68).

Pensar a cultura dentro da educação, a partir dos Estudos Culturais, é focalizar "os termos da aprendizagem em torno de questões relacionadas às diferenças culturais, ao poder, e a história" (GIROUX, 2005, p. 94). É pensar nesses diferentes espaços que nos permeiam e que, através de suas pedagogias, nos educam e nos constituem enquanto sujeitos.

Nesse sentido, objetivamos traçar nesta pesquisa e nas análises propostas, discussões que nos permitam pensar e refletir sobre as sexualidades e os gêneros, pensando em estratégias para promoção de uma educação para a sexualidade desde a infância. 


\subsection{Dos artefatos às pedagogias culturais: possibilidades no espaço escolar e nos livros infantis}

Os livros selecionados são importantes artefatos culturais, pois podem ser utilizados desde a Educação Infantil até as séries iniciais do Ensino Fundamental, já que são artefatos que fazem parte do cotidiano das crianças. Segundo Guerra (2005, p. 70) "não só os brinquedos, mas outros artefatos culturais têm sido acionados para a educação das crianças". Ainda nas contribuições da autora, é possível entender que:

Os artefatos culturais [...] não podem ser vistos somente como diversão e prazer, mas merecem ser olhados de forma crítica, pois fazem parte do cotidiano das crianças e estão atravessados por definições de condutas, de comportamentos e de sentimentos considerados adequados socialmente para meninos e meninas, contribuindo nas constituições das identidades de gênero e sexuais (Ibid. 2005, p. 70).

Nesse sentido, pensar nos livros como artefatos culturais e como importantes componentes e instâncias que também ensinam algo, nos permite entender que

Os artefatos culturais produzem significados [...]. Entender os livros como artefatos culturais e que expressam pedagogias nos leva a analisar os textos e ilustrações e buscar problematizações sobre os conceitos, sobre formas de instigar a reflexão e a autorreflexão dos sujeitos leitores (XAVIER FILHA, 2014, p. 234).

Nossa intenção sobre estes artefatos é observar, a partir das suas pedagogias culturais, como "são produzidas e reproduzidas numa variedade de locais sociais e como movem as pessoas à ação e colocam limites à gama de possibilidades através das quais os indivíduos negociam suas identidades e seu sentido de agência social". (GIROUX, 2005, p. 136). Olhamos para estes materiais como peças norteadoras, as quais propõem incluir a criança na participação de discussões sobre a diversidade sexual e de gênero; no entanto, é importante pensar sobre o entendimento que a criança já estabeleceu segundo estas temáticas, oportunizando às mesmas reflexão e discussão a partir do que já sabem e do que estes artefatos lhe proporcionaram pensar.

De tal maneira, torna-se relevante olharmos para o Acervo Complementar do PNAIC enquanto artefatos que se inserem nas escolas e que podem ser utilizados para a promoção de discussões relacionadas à diversidade sexual e de gênero. Nesse viés, abordamos a literatura utilizando-a como recurso que aproxima as crianças de outras representações e possibilidades, que muitas vezes demarcam o gênero e a sexualidade e não são discutidas dentro da escola. Conforme Abramovich (2009, p. 14), 
A literatura (...) é também suscitar o imaginário, é ter a curiosidade respondida em relação a tantas perguntas, é encontrar outras ideias para solucionar questões (como as personagens fizeram). É uma possibilidade de descobrir o mundo imenso dos conflitos, dos impasses, das soluções que todos vivemos e atravessamos - dum jeito ou de outro - através dos problemas que vão sendo defrontados, enfrentados (ou não), resolvidos (ou não) pelas personagens de cada história (cada uma a seu modo). [...] é ouvindo histórias que se pode sentir (também) emoções importantes, como a tristeza, a raiva, a irritação, o bem-estar, o medo, a alegria, o pavor, a insegurança, a tranquilidade, e tantas outras mais, e viver profundamente tudo o que as narrativas provocam em quem as ouve - com toda a amplitude, significância e verdade que cada uma delas fez (ou não) brotar [grifos da autora]).

Assim, ainda sobre os livros, entendemos que estes permitem uma reflexão e discussão sobre um cenário de rejeição e preconceito, resultando muitas vezes na distinção dos gêneros, como o que pode ser direcionado às meninas e aos meninos. Para Louro (2013b, p. 45-46),

Uma noção singular de gênero e sexualidade vem sustentando currículos e práticas de nossas escolas. Mesmo que se admitam que existem muitas formas de se viver o gênero e a sexualidade, é consenso que a instituição escolar tem obrigação de nortear suas ações por um padrão: haveria apenas um modo adequado, legítimo, normal de masculinidade e feminilidade e uma única forma normal e sadia de sexualidade, a heterossexualidade; afastar-se desse padrão significa buscar o desvio, sair do centro, tornar-se excêntrico.

Entendemos, portanto, que o conjunto dessas reflexões indica que "nos dias atuais, não é mais possível que as questões relativas à sexualidade passem despercebidas ou que sejam tratadas com deboches ou indignação" (CAMARGO e RIBEIRO, 1999, p. 43). Nessa perspectiva, nos debruçamos a olhar como o Programa do Pacto aborda essas temáticas e quais possibilidades de discussão oferece às/aos professoras/es.

As autoras Felipe, Guizzo e Beck (2013) já vêm destacando a relevância de desenvolver "estudos e pesquisas que articulam os temas infância-gênero-sexualidade, especialmente no campo da educação" (p. 23) por entender que,

[...] As pedagogias culturais e as pedagogias da visualidade são de extrema relevância na constituição das identidades infantis. Notoriamente, diferentes esferas sociais e culturais produzem educação, e as práticas pedagógicas desenvolvidas por essas esferas mostrando-se revestidas por uma espécie de novo "código de civilidade", fixando a necessidade de uma formação/educação que se dá na relação dos sujeitos com os numerosos signos postos no contemporâneo (Ibidem. [grifos da autora]).

Neste viés, nos valemos dessas pedagogias a fim de apresentar os livros como artefatos que nos educam através de suas práticas discursivas, as quais produzem uma rede de significados. Nessa proposta, nossa investigação sobre estes artefatos nos direciona a um 
olhar sobre as representações que se estabelecem em suas pedagogias culturais, entendendo que é importante pensar e refletir sobre o que podemos oportunizar às crianças para que elas possam "expressar livremente suas concepções e análises diversas, e não apenas uma verdade única transformada em dogma" (Ibid., 2013, p. 114). A partir dessa discussão, entendemos que os Livros Infantis que compõe o Acervo Complementar do PNAIC se constituem dessas pedagogias, oportunizando um contato da criança com temas atuais.

Sobre essas pedagogias culturais, Xavier Filha (2014, p. 51) vai nos dizer que elas existem

[...] em todo espaço social e cultural que apontam as formas desejáveis de ser menina, de ser menino, de bem portar-se, de viver masculinidades e feminilidades, de vivenciar expressões de sexualidade, entre outras formas de exercer identidades e subjetividades (p. 51).

Giroux (2005, p. 154) amplia a possibilidade das pedagogias instituindo estes materiais como aparatos culturais, pois também constituem um envolvimento sobre "a formação de diferentes subjetividades sociais e também na construção de identidades". Utilizar artefatos culturais como propostas pedagógicas "significa ampliar o significado e a prática da pedagogia para além das fronteiras da escola" (Ibid.2005, p. 155). Nas palavras de Sabat (2001, p. 30), é possível entender que

Tais pedagogias, entre outras coisas, produzem valores e saberes; regulam condutas e modos de ser; fabricam identidades e representações; constituem certas relações de poder. [...] As representações de gênero e sexualidade e nesse contexto argumento que existem formas determinadas de pedagogia e de currículo sendo operadas em diversas instâncias sociais, por diferentes artefatos culturais.

Assim, percebemos que os livros analisados nessa pesquisa ensinam modos de ser, agir, representar, comportamentos para meninos e meninas, como outras discussões que estão relacionadas à família. Por este motivo são tratados como artefatos culturais, pois educam a partir das suas possibilidades de pensar e refletir sobre as diversidades e sobre os processos e espaços por meio dos quais nos constituímos enquanto sujeitos.

Assim, é possível entendermos que os estudos de gênero auxiliam a desconstruir a ideia das diferenças inatas, ou seja, defendem que as diferenças entre homens e mulheres não podem ser caracterizadas pelo fator biológico, mas sim devem ser entendidas enquanto construções culturais.

O conceito de gênero surgiu a partir das contribuições e da militância dos movimentos sociais feministas, os quais lutavam pela igualdade de seus direitos políticos, civis e sociais. Essas lutas foram ganhando força na medida em que seus objetivos de conquista aumentavam, 
e a partir das grandes manifestações em Londres as mulheres acabaram conquistando o direito ao voto (LOURO, 2013a).

[...] na virada do século, as manifestações contra a discriminação feminina adquiriram uma visibilidade e uma expressividade maior no chamado "sufragismo", ou seja, no movimento voltado para estender o direito do voto às mulheres. Com uma amplitude inusitada, alastrando-se por vários países ocidentais (ainda que com força e resultados desiguais), o sufragismo passou a ser reconhecido, posteriormente como a "primeira onda" do feminismo (LOURO, 2013a, p. 19 [grifo da autora]).

A partir da segunda onda do Feminismo que ocorre no final da década de 1960, as feministas passam a argumentar “contra 'determinismo biológico' e a favor do "construcionismo social"” (HARAWAY, 2004, p. 18 [grifos da autora]). Assim, o conceito de gênero contesta e modifica a naturalização empregada à diferença sexual, a qual coloca homens e mulheres em situações, lugares e posições diferentes. Nesse contexto, "gênero contrapõe-se às concepções pautadas em uma essência (masculina ou feminina) natural, universal e imutável, enfatizando os processos de construção ou formação linguística, histórica e socialmente determinada" (FELIPE; GUIZZO; BECK, 2013, p. 22). Segundo Meyer (2005, p. 17), o conceito de gênero enfatiza

a pluralidade e conflitualidade dos processos pelos quais a cultura constrói e distingue corpos e sujeitos femininos e masculinos, torna-se necessário admitir que isso se expressa pela articulação de gênero com outras "marcas" sociais, tais como classe, raça, etnia, sexualidade, geração, religião, nacionalidade. É necessário admitir também que cada uma dessas articulações produz modificações importantes nas formas pelas quais as feminilidades ou as masculinidades são, ou podem, ser, vividas e experienciadas por grupos diversos, dentro dos mesmos grupos ou ainda, pelos mesmos indivíduos, em diferentes momentos de sua vida ([grifos da autora]).

Podemos perceber por meio das contribuições da autora que os gêneros não se dão somente nas discussões relacionadas aos padrões de comportamentos masculinos e femininos, mas sim nas construções que perpassam as culturas, sociedades e nos diferentes ambientes nos quais estamos inseridos, bem como nas relações de poder. É nessa relação de poder que as discussões sobre o gênero se tornam essenciais nos diferentes espaços aos quais pertencemos.

Stuart Hall (2014) vai nos mostrar que o feminismo apresentou aspectos novos nas lutas políticas a partir do momento que abordou temas como família, sexualidade, trabalho doméstico e cuidados com as crianças, explicando que esse movimento

enfatizou, como uma questão política e social, o tema da forma como somos formados e produzidos como sujeitos generificados. Isto é, ele politizou a subjetividade, a identidade e o processo de identificação (como homens/mulheres, mães/pais, filhos/filhas).... Aquilo que começou como um 
movimento dirigido à contestação da posição social das mulheres, expandiuse para incluir a formação das identidades sexuais e de gênero (p.28).

No permear das lutas, as discussões relacionadas aos gêneros e às sexualidades foram ganhando espaço e se tornando temas de debate em diferentes espaços. Logo, Michel Foucault (2014) nos apresenta a sexualidade como um dispositivo histórico, sendo ela construída historicamente e culturalmente a partir da linguagem, dos discursos, das relações de poder e das verdades, que, muitas vezes, normatizam os sujeitos. Conforme Foucault (2014, p. 115), “A sexualidade é o nome que se pode dar a um dispositivo histórico [...] em que a estimulação dos corpos, a intensificação dos prazeres, a incitação ao discurso, a formação dos conhecimentos, encadeiam-se uns aos outros".

Refletir sobre as incitações ao discurso requer que se pense sobre "a multiplicação dos discursos sobre o sexo no próprio campo do exercício do poder: incitação institucional a falar do sexo e a falar dele cada vez mais” (Ibid., p. 20). Para Maio (2011, p. 28):

[...] a sexualidade é tanto um produto da linguagem e de um processo cultural, histórico, quanto da natureza. Dizer que a sexualidade é um processo "natural", inerente ao ser humano, é ancorar-se na suposição de que todas as pessoas vivem e manifestam-se sexualmente de maneira universal. Porém, ao contrário, a sexualidade [...] envolve rituais, linguagens, fantasias, representações, símbolos, convenções ([grifo da autora]).

Pensar a sexualidade como uma construção social que se (re)constitui a partir das linguagens e das representações possibilita perceber "a sexualidade, bem como a respectiva educação, configurada sob a forma de educação sexual, ou mesmo em educação para a sexualidade, reflete os elementos culturais e históricos de uma determinada época" (XAVIER FILHA, 2010. p. 4).

Para Toniette (2006, p.42),

[...] falar da história da sexualidade humana é resgatar elementos para se compreender significados e sentidos dessa construção social, com a proposta de reconhecer as diversas constituições e possibilidades de sexualidade que vislumbram na atualidade.

Foucault (2014) aponta que, a partir das práticas de encerramento e do silêncio, falar em sexo era restrito somente à família, sendo ela o exemplo "legítimo e procriador, dita a lei. Impõe-se como modelo, faz reiniciar a norma, detém a verdade, guarda o direito de falar, reservando-se o princípio do segredo" (p. 7). Para Ribeiro (2013), “a sexualidade está presente desde a mais terna idade. A sua manifestação na infância é vigiada e controlada pelos 
adultos que tentam a qualquer custo ignorar e/ou reprimir, sob a premissa de que a infância é assexuada" (p. 62).

Na contemporaneidade, as práticas pelas quais somos constituídas/os e subjetivadas/os ainda aparecem imersas nessas discussões. O que percebemos é que a escola faz seu investimento no disciplinamento e no cuidado do corpo - sua resistência na inserção de uma pedagogia da sexualidade tira a responsabilidade da escola de realizar este trabalho. Segundo Louro (2013c, p. 25),

a despeito de todas as oscilações, contradições e fragilidades que marcam esse investimento cultural, a sociedade busca, intencionalmente, através de múltiplas estratégias e táticas, "fixar" uma identidade masculina e feminina "normal" e duradoura. Esse intento articula, então, as identidades de gênero "normais" a um único modelo de identidade sexual: a identidade heterossexual. Nesse processo, a escola tem uma tarefa bastante importante e difícil. Ela precisa se equilibrar sobre em fio muito tênue: de um lado, incentivar a sexualidade "normal" e, de outro, simultaneamente, contê-la ([grifos da autora]).

É possível perceber que as 'verdades' instituídas sobre as sexualidades e os gêneros necessitam de mais atenção e discussão no espaço escolar, entendendo que a escola ainda exerce atitudes conservadoras, que se refletem em estereotipias que discriminam e que sempre buscam separar homem e mulher - ou até mesmo reforçam algumas ações de masculinidade e superioridade desse gênero em relação à mulher e ao feminino.

Nessa continuidade, é necessário falarmos sobre nosso entendimento acerca dos conceitos de identidade e diferença, o que nos permite pensar sobre a diversidade sexual e de gênero. Para tanto, tomamos como referência os estudos de Silva (2014, p. 9), que compreende que "a identidade é, assim, marcada pela diferença", ou seja, como nos construímos culturalmente diferente do outro. Para o autor, "a cultura molda a identidade ao dar sentido à experiência e ao tornar possível optar, entre várias identidades possíveis" (p.19).

Portanto, é possível entender que as relações existentes entre a diferença e a identidade mantêm sempre um processo constante de dependência uma da outra, pois ao afirmar o que sou, apresento as diferenças daquilo que o outro é. Como afirma Silva (2014, p. 74),

a identidade é simplesmente aquilo que se é: "sou brasileiro", "sou negro", "sou heterossexual", "sou jovem", "sou homem". A identidade assim concebida parece ser uma positividade ("aquilo que sou"). [...] Da mesma forma que a identidade, a diferença é, nesta perspectiva concebida como autorreferenciada como algo que remete a si própria. A diferença, tal como a identidade, simplesmente existe ([grifos do autor]). 
Silva (2014) também chama atenção para as relações de poder, bem como para os processos de produção simbólica e discursiva que tramam as redes entre a identidade e a diferença, ao afirmar que " a identidade, tal como a diferença, é uma relação social. Isso significa que sua definição - discursiva e linguística - está sujeita a vetores de força, a relações de poder. Elas não são simplesmente definidas; elas são impostas [...] elas são disputadas" (p. 81). O autor ainda destaca que:

A identidade e a diferença estão, pois, em estreita conexão com relações de poder. O poder de definir a identidade e de marcar a diferença não pode ser separado das relações mais amplas de poder. A identidade e a diferença não são nunca inocentes $(\mathrm{p}, 81)$.

Assim, pensar a diversidade sexual e de gênero significa refletir sobre as diferenças, linguagens, representações e transformações, as quais nos permitem entender as diferentes estratégias sociais e também políticas para se pensar em uma educação para a sexualidade. Tomamos o conceito de educação para a sexualidade a partir dos estudos da autora Xavier Filha (2009, p. 97), ao entender que,
a perspectiva da educação para a sexualidade pretende refletir sobre discursos naturalizados e sacralizados culturalmente, revitalizando-os, pondo-os sob suspeita e vigilância, provocando a dúvida de algumas certezas, permitindo-se novas formas de pensar e com isso estimular questionamentos sobre como nos constituímos em relações de saber e poder. Com isso desestabilizar certezas, na tentativa de ampliar olhares em outras direções e possibilidades.

Assim, desfiamos este fio de possibilidades ao tentar apresentar outras formas de discutir e entender estes artefatos - os livros do Acervo Complementar e os Materiais do PNAIC - como produtores de conhecimento, de modos de pensar e de agir. Tais artefatos são constituídos por pedagogias culturais, apresentando conceitos, valores e sujeitos múltiplos e plurais, os quais vão se reconfigurando a cada dia, nos possibilitando refletir sobre a diversidade; neste caso, as diversidades sexual e de gênero.

Para Furlani (2005), "os gêneros e as sexualidades são constantemente produzidos e, se poderia dizer ensinados por meio de suas representações" (Ibid.2005, p. 32). Entendemos assim que no espaço escolar as representações estão visivelmente expressas por meio de cartazes, livros, roupas, modos de comportamento, do que se fala (linguagem) e do que se faz; portanto, "a forma como cada representação interpreta o sujeito vai depender do significado culturalmente estabelecido" (Ibid. 2005, p.33).

Trabalhar analisando também a representação se torna fundamental para nossa análise, pois "vários outros textos no âmbito da escola geram e circulam saberes acerca dos gêneros e das sexualidades: regulamentos, atividades, livros didáticos e paradidáticos" (FURLANI, 
2005. p. 32). É pertinente demostrar que há uma possibilidade de desconstrução das verdades naturalizadas, e que ainda se fazem presentes nas representações dos diferentes materiais, como os artefatos selecionados para análises nessa pesquisa.

Assim, entendemos que as discussões ainda estão longe do que seria necessário dentro do espaço escolar; entretanto, pensamos que esses artefatos podem auxiliar no debate da diversidade sexual e de gênero dentro da escola. É o que nos provoca pensar a autora Xavier Filha (2009, p. 97), ao falar que a educação para a sexualidade pretende refletir

sobre discursos naturalizados e sacralizados culturalmente, revitalizando-os, pondo-os sob suspeita e vigilância, provocando a dúvida de algumas certezas, permitindo-se novas formas de pensar e com isso estimular questionamentos sobre como nos constituímos em relações de saber e poder. Com isso desestabilizar certezas, na tentativa de ampliar olhares em outras direções e possibilidades.

Dessa maneira, as políticas públicas da educação que pautam a diversidade sexual e de gênero como temas relevantes, refletidas nas práticas pedagógicas das/os professoras/es e em ações de formação continuada, tornam-se peças fundamentais frente ao cenário de preconceitos e discriminações sexuais e de gênero que observamos em nossa sociedade.

A partir desses entendimentos, podemos pensar a educação - e em especial o PNAIC enquanto integrantes do dispositivo da sexualidade, agenciados pelas tecnologias de controle do biopoder e da governamentalidade. Por esse viés, percebemos o quanto é relevante olhar para o PNAIC e seus artefatos como possíveis promotores dessas discussões, percebendo como são representadas essas temáticas dentro do programa e também na formação de professoras/es que o mesmo promove, possibilitando às/aos integrantes destes espaços interagir e discutir, a partir de sua realidade, sobre acontecimentos e assuntos que perpassam o ambiente escolar e também familiar.

A partir desses entendimentos e pressupostos teóricos, apresentamos a seguir o que estamos entendendo por infâncias, governamentalidade e biopolítica, e como estes conceitos nos ajudam a pensar o PNAIC enquanto uma estratégia biopolítica.

\subsection{Infância - governamentalidade e biopolítica}

[...] no contexto contemporâneo estão surgindo, como tais políticas, novas formas de governamento da infância que terão efeito na vida dessas crianças. São novas formas, novas estratégias que visam a um controle maior. (MOTA, 2010b, p.79)

A infância (ou digamos, as infâncias) vem se tornando foco central de estratégias de governamento. Assim, como salienta Mota (2010), cada vez mais novas estratégias de 
controle são pensadas para elas. $\mathrm{Na}$ escrita que segue tencionamos a contextualizar a construção social das infâncias na intenção de apresentar seu surgimento histórico, assim como o aparecimento de pedagogias destinadas às crianças e algumas estratégias de governamento e biopolítica como, no caso dessa pesquisa, o PNAIC.

Na obra, História social da criança e da família, publicada em 1960 pelo pesquisador Philippe Ariés (1981), o autor traz a informação de que o conceito e a ideia de 'infância' vem sendo transformada e construída ao longo dos anos - desde que as crianças eram percebidas e tratadas como mini adultos e compartilhavam diversos momentos junto aos adultos, os quais nunca mantinham preocupação em privá-las de assuntos 'imorais'.

As brincadeiras, jogos, ritos e festividades faziam parte tanto da vida adulta quanto da vida das crianças. Elas estavam presentes em diferentes contextos e misturavam-se entre os adultos, sua relação era indiscriminada, pois as crianças presenciavam situações vulgares de brigas, conversas com palavras grosseiras e jogos sexuais. $\mathrm{O}$ fato de não se acreditar na inocência das crianças permitia aos adultos manter uma total liberdade perante elas. Sobre isso Postman (1999) nos diz que

as crianças compartilhavam os mesmo jogos com os adultos, os mesmos brinquedos, as mesmas histórias de fadas. Viviam juntos, nunca separados. A festa vulgar de aldeia pintada por Brueghel, mostrando homens e mulheres embriagados, apalpando-se com luxúria desenfreada, inclui crianças comendo e bebendo com os adultos. (p.30)

Na Europa entre os séculos XVI e XVII, Comenius (1593), Rosseau (1712) e Pestalozzi (1746) apresentaram suas contribuições acerca da valorização das infâncias. As crianças, até então consideradas mini adultos, passaram a contar com propostas inovadoras e protetoras. Porém, Foucault (2014) nos aponta que

No início do século XVII ainda vigorava uma franqueza. As práticas não procuravam o segredo; as palavras eram ditas sem reticência excessiva e as coisas eram feitas sem demasiado disfarce; tinha-se com o ilícito uma tolerante familiaridade. Eram frouxos os códigos da grosseria, da obscenidade, da decência, se comparados com os do século XIX. Gestos diretos, discursos sem vergonha, transgressões visíveis, anatomias mostradas e facilmente misturadas, crianças astutas vagando, sem incômodo nem escândalo, entre os risos dos adultos: os corpos "pavoneavam". (p.7 [grifos do Autor]).

Nesta época, existia um índice de mortalidade infantil muito grande, não havendo uma preocupação com o ser infantil, tampouco um sentimento de perda, como expressa uma passagem de Ariés (1981) ao ver uma vizinha tranquilizar outra “mãe de cinco 'pestes', e prestes a dar à luz: antes que eles te possam causar muitos problemas, tu terás perdido a 
metade, e quem sabe todos" (p. 22). Percebe-se aí a falta de sentimento, de perda e cuidado em relação às crianças.

Já no século XIII surgem as representações das crianças mais próximas do pensamento moderno, representadas por imagens de anjos "sob a aparência de um rapaz muito jovem" (ARIÉS, 1981, p. 18). No século XIV, a imagem da criança era representada por um modelo ancestral de todas as crianças, "o Menino Jesus, ou Nossa Senhora menina, pois a infância aqui se ligava ao mistério da maternidade da Virgem e ao culto de Maria" (Ibid., p. 19). Sobre essa época, Ariés (Ibid.) nos diz que

$\mathrm{Na}$ vida quotidiana as crianças estavam misturadas com os adultos, e toda reunião para o trabalho, o passeio ou o jogo reunia crianças e adultos; segundo, a ideia de que os pintores gostavam especialmente de representar a criança por sua graça ou por seu pitoresco (o gosto do pitoresco anedótico desenvolveu-se nos séculos XV e XVI e coincidiu com o sentimento da infância "engraçadinha”) (p. 21 [grifos do autor]).

Tal representação acaba por promover o surgimento do sentimento de paparicação, que é expressado por um olhar especial sobre a criança. O sentimento de apego e paparicação propõe separar as crianças do meio adulto para que estas tivessem a possibilidade de uma educação disciplinada. Neste viés, foram sendo tecidas as teias que perpassavam os acontecimentos e as construções acerca das infâncias.

A educação familiar foi tomando uma configuração mais nuclear, não perdendo sua característica conservadora e patriarcal. Com a evolução das relações sociais, as crianças passam a ter um papel central, sendo percebidas como atores sociais.

Bujes (2002), no livro intitulado Infância e Maquinarias, nos provoca a pensar na ideia de que os significados atribuídos às infâncias são consequências das modificações políticas, econômicas, sociais, bem como resultados de processos históricos e sociais, os quais "dependem de um conjunto de possibilidades que se conjugam em determinado momento da história, são organizados socialmente e sustentados por discursos nem sempre homogêneos e em perene transformação" (Idbem, 2002, p. 24 -25).

A autora reitera que as infâncias são uma invenção, uma fabricação da modernidade, e que todas as transformações e os acontecimentos relacionados a ela vão ganhando novas configurações. Assim, existe a necessidade de mecanismos de controle e poder em tornar estes corpos infantis em corpos dóceis e úteis, e "para regular tais processos e as condições para fazê-los variar, estabelecem-se intervenções e controle, no que vem a se constituir numa biopolítica da população" (BUJES, 2002, p. 35). 
No decorrer dessas mudanças é que se organizam as instituições educacionais, passando a educação das infâncias a se inserir neste conjunto de tecnologias políticas, as quais investem em processos de controle e normalização (BUJES, 2002).

Foucault, em alguns de seus livros como Microfísica - Segurança, Território, População (1978) e Nascimento da Biopolítica (1979), apresenta discussões e provocações, as quais parecem se relacionar com questões de ordem política da contemporaneidade e o governamento das infâncias. $\mathrm{O}$ autor dedica-se a ideia de 'governar' aplicada à conduta dos homens, ampliando este conceito para governamentalidade. Segundo Filho (2006, p. 19), este conceito de governamentalidade se apresenta

[...] articulando-se a saberes sobre os sujeitos: incide sobre corpos individuais e coletivos regulando, marcando, normalizando e individualizando; induz efeitos de subjetividade, produz subjetivações; concerne à vida dos indivíduos, dirige-se à sua conduta; envolve técnicas de governo de si mesmo.

Assim, é possível perceber que "a escola é o alvo de governamento. O alvo são os sujeitos infantis, mas as práticas se dão por meio das instituições escolares" (MOTA, 2010, 129). Além disso, as políticas educacionais estão pautadas na arte governamental, ou seja, podemos dizer que tais políticas apresentam estratégias de controle visando reduzir o fracasso escolar e o alcance de maiores índices de qualidade na educação.

Diante desse contexto, é possível pensar que essas políticas educacionais, e no caso particular desta pesquisa, o PNAIC, vêm se configurando como uma estratégia bastante eficaz para o governo da população infantil. No entanto, cabe salientar que nosso intuito é destacar e discutir alguns pontos sob a governamentalidade, a partir dos quais propomos compreender questões de políticas públicas educacionais contemporâneas - especialmente as que apresentamos como objetivo desta pesquisa, sobre diversidade sexual e de gênero a partir do Acervo Complementar do PNAIC. Ao debruçar-se sobre as redes de poder-saber, Foucault constata que foi a partir de uma crise do poder pastoral que se constituíram diferentes estratégias de governar os outros e a si mesmo.

Durante o século XVI, o problema do governo se apresenta de diferentes formas e múltiplos aspectos, como um "problema do governo de si mesmo, problema do governo das almas e das condutas, problema do governo das crianças, problema do governo do Estado pelos príncipes" (ibdem, p. 277). E até o fim do século XVIII vê-se desenvolver uma série de 
tratados que não se destinam aos príncipes ${ }^{2}$ como conselhos, nem tampouco como ciência da política, mas sim como a arte de governar (FOUCAULT, 1978). Caracteriza-se, assim, não um poder exclusivo do príncipe, mas agora como múltiplos poderes, apresentando-se como técnica de governar, ou diferentes formas de governo.

As transformações ocorridas entre os séculos XVIII até o século XIX geraram o que podemos chamar de 'biopolítica', ou seja, técnicas de governo que tendem a governar não só os indivíduos por meio de procedimentos disciplinares, mas também a população e as infâncias, como destacamos nessa pesquisa. Mota (2010c) destaca que "para gerir a vida, é necessário a produção de saberes sobre uma determinada população, de forma a obter um maior controle sobre elas. E isso é feito a partir de estratégias biopolíticas” (p. 75).

No caso desta pesquisa, podemos compreender que o Pacto Nacional pela Alfabetização na Idade Certa pode ser pensado como uma estratégia de governamento da população infantil, pois utiliza-se de diferentes estratégias de controle sobre as crianças alfabetização, sua participação na escola, comportamento e os índices escolares relativos à aprendizagem das crianças - caracterizando-se, assim, como uma biopolítica de controle.

Esse entendimento do PNAIC enquanto uma biopolítica é um dos focos da discussão que pretendemos investir na sessão seguinte às análises. Nesse processo, nosso olhar sobre o PNAIC visa discutir sobre as estratégias de controle, discorrendo assim sobre as diferentes técnicas de poder sobre as crianças, as quais atuam com o objetivo de garantir um padrão educacional e também de controle dos corpos, garantindo o sucesso na alfabetização e nos índices de qualidade educacional.

\section{Caminhos da constituição do PNAIC}

O PNAIC teve sua efetivação em 2012, porém é possível dizer que o PNAIC surgiu a partir de outro Programa já em execução no Estado do Ceará. Foi a partir dos avanços obtidos na alfabetização que transformaram esse Estado em referência (GOMES, 2013).

O Programa de Alfabetização na Idade Certa (PAIC) como é constituído no Ceará é executado pela Secretaria de Educação (SEDUC-CE) desde o ano de 2007. O PAIC obteve seu êxito na medida em que conseguiu reverter o quadro dos baixos níveis de alfabetização nas instituições cearenses.

\footnotetext{
${ }^{2}$ Na Idade Média ou na Antiguidade Greco Romana, sempre existiram tratados que se apresentavam como conselhos aos príncipes, quanto ao modo de se comportar, de exercer o poder, de ser aceito ou respeitado pelos súditos e pelas leis dos homens de Deus (FOUCAULT, 1978, p. 277).
} 
O PAIC é considerado uma iniciativa exitosa por ter revertido o quadro de baixos níveis de alfabetização identificado entre as crianças cearenses. De acordo com o Sistema Permanente de Avaliação da Educação Básica do Ceará-Alfabetização

(SPAECE-Alfa), em 2007 apenas $26 \%$ dos Municípios cearenses apresentavam médias de desempenho consideradas suficiente ou desejável para os alunos concluintes do $2^{\circ}$ ano do ensino fundamental. Em 2010, o percentual de localidades agrupadas nesses dois níveis alcançou 99\% (GOMES, 2013, p. 11).

O referido Programa tem apoio de cinco eixos, os quais auxiliam na efetivação de sua proposta, sendo estes: gestão municipal de educação, avaliação externa, alfabetização, formação do leitor e a educação infantil, o Estado do Ceará, torna-se estrutura modelo para o que vem a se constituir em nível nacional o PNAIC (GOMES, 2013).

Ao entender a necessidade e o investimento para uma educação de qualidade, o PNAIC, foi destinado não só às escolas urbanas, mas também às escolas localizadas nas zonas rurais, assim o MEC, buscou priorizar "as especificidades das escolas do campo, as quais foram incorporadas no conteúdo da formação e foram desenvolvidos cadernos de estudo específicos para os professores das turmas multisseriadas e multietapas” (BRASIL, 2012, p.15).

Neste viés, de acordo com o Programa PNAIC, o mesmo não se destina somente e exclusivamente à alfabetização, mas para além dessa, destina-se também à "ampliação de seu universo de referências culturais, nas diferentes áreas do conhecimento" (ibid., p.17).

O PNAIC estabeleceu desde sua constituição oferece cursos de Formação Continuada para professoras/es da rede pública Municipal e Estadual de ensino. Preocupado com a formação integral e continuada para além da graduação, o MEC, investe na proposta de ofertar estes cursos.

Dessa maneira, entende-se que a formação do professor não se encerra na conclusão do seu curso de graduação, mas se realiza continuamente na sala de aula, onde dúvidas e conflitos aparecem a cada dia. Uma das possibilidades de superação de dificuldades é a oportunidade de discutir com outros profissionais da educação, o que pode favorecer a troca de experiências e propiciar reflexões mais aprofundadas sobre a própria prática. Isso só é possível quando a formação é integrada ao cotidiano da escola, com garantia de ambiente adequado e tempo para os momentos individuais e coletivos de estudo, sem prejuízo dos dias e horas letivos, assegurando os direitos dos estudantes (BRASIL, 2012, p. 23).

A organização da formação continuada do PNAIC ocorre em dois momentos. Primeiramente, para Orientadoras/es de Estudos (OE), essas/esses orientadoras/es de estudo são professoras/es da rede Municipal e Estadual, que fizeram o curso específico completando 200 horas de duração por ano, constituído por um encontro de 40 horas (imersão), quatro 
encontros de 24 horas cada um, totalizando 96 horas, seminários, atividades de monitoramento e planejamento, totalizando 64 horas. Esse curso é ministrado por universidades públicas parceiras ao MEC. Na Região Sul as universidades parceiras nessa formação são as Universidades Federais de Pelotas/ UFPEL e Santa Maria/ UFSM (BRASIL, 2012).

\section{Caminhos metodológicos - pesquisa documental e análise cultural: ferramentas para a análise dos artefatos}

$\mathrm{Na}$ intenção de analisar as possibilidades de discussão sobre diversidade de gênero e sexual a partir dos artefatos que constituem o PNAIC, elencamos a pesquisa documental como uma ferramenta para a seleção destes dados de análise. Como isso pretendemos identificar, analisar e refletir sobre os documentos selecionados de acordo com essa proposta.

Os documentos selecionados para compor os dados de análise da pesquisa são destinados às/aos professoras/es da rede Municipal e Estadual de Educação básica, contemplando os três primeiros anos do Ensino Fundamental.

\section{O Caderno de Formação de Professores no Pacto Nacional pela Alfabetização na}

Idade Certa tem por objetivo auxiliar na formação das/os professoras/es do PNAIC no ciclo de alfabetização, apresentando estratégias e orientações para a rotina de formação e prática destas/es professoras/es no espaço escolar. O Manual de Apresentação: Pacto Nacional pela Alfabetização na Idade Certa objetiva apresentar o Programa e suas estratégias de alfabetização para o ciclo dos três primeiros anos do Ensino Fundamental. O Acervo Complementar constituídos por 6 caixas, em que cada caixa contém 30 obras literárias destinadas ao público infantil de faixa etária de seis a oito anos, formando um total de 180 obras infantis (BRASIL, 2012).

Segundo Ludke e André (1986), a utilização da pesquisa documental para a produção dos dados nos possibilita organizar e analisar as informações contidas nos livros, de maneira que seja possível destacar as representações, discussões e discursos de acordo com os temas propostos pela/o pesquisadora/or. A seleção dos documentos, assim como a organização, corresponde à problemática e a intensão a qual a/o pesquisadora/or tem sobre tal análise.

De acordo com nossos critérios, elencamos quatro obras que nos permitem esse olhar sobre a diversidade sexual e de gênero, são elas: O menino Nito: - Então homem chora ou não?( Sonia Rosa, Editora Pallas, 2011), Lilás uma menina diferente (Mary Whitcombo, Editora Cosac Naify, 2009), Carta do tesouro (Ana Miranda, Editora Armazém da Cultura, 
2009) e o Grande e maravilhoso livro das famílias (Mary Hoffman, Editora SM edições, 2010).

Neste entendimento, a partir dessas pedagogias e os processos de construção social do sujeito, é que propomos o estudo dessa pesquisa. Pensando nas possibilidades que esta poderá suscitar dentro e fora do ambiente escolar, tanto para as crianças quanto para as/os professoras/es. Nesse caminho, apostamos na literatura e utilizamos este artefato por fazer parte do cotidiano das crianças, podendo interpretá-la a partir das figuras, personagens, das representações, promovendo uma troca de entendimentos por parte das crianças e professoras/es. Segundo Xavier Filha (2014, p. 157):

(...) Mesmo os livros destinados à infância que tratam de outras temáticas e que são considerados como literatura infantil, mesmo na ausência de objetivos educativos explícitos sobre determinados assuntos, isto é, aqueles tomados como obras artísticas, também educam. É a partir desse pressuposto que os estudos culturais nos possibilitam entender os livros como artefatos culturais. Independentemente de serem considerados literatura, todos educam, de alguma forma. Eles expressam modos de ser menina ou menino e produzem no leitor ou leitora maneiras de ser no mundo, de pensar, de construir problemas, de confrontar-se com a realidade e consigo mesmo/a, tudo em um tipo de relação específica estabelecida com a leitura.

Desse modo, apresentamos a análise cultural como metodologia de análise, formulada a partir do campo teórico dos Estudos Culturais e suas vertentes pós-estruturalistas, afim de, comtemplar a cultura como uma produção social delineada pelas transformações contemporâneas, a qual nos permite entender os livros como artefatos culturais, e realizar análises a partir de suas representações e discursos. Graeme Turner (apud WORTMANN, 2007) complementam este entendimento ao destacar que as análises culturais,

[...] ganham importância por darem visibilidade a aspectos e relações não referidas em análises tradicionais, como as que tratam, por exemplo, das negociações ocorridas no cotidiano dos sujeitos, as quais têm, [...] inegável efeito e influência em suas vidas (p.74).

Dentro da perspectiva dos Estudos Culturais não existe uma única metodologia distinta, "os Estudos Culturais se aproveitam de quaisquer campos que forem necessários para produzir o conhecimento exigido por um projeto particular" (TREICHLER e GROSSBERG, 1995, p. 9).

Essa forma de análise parte da problematização das produções e das manifestações culturais. Para entender a cultura Wilhiams (2011 [1974]) propôs pensar sobre os modos de vida e os valores da comunidade, observando os benefícios e custos na maneira pela qual são representados. Desenvolveu-se a partir dessa observação o materialismo cultural, inspirado 
em Karl Marx, "segundo o qual as pessoas produzem suas próprias condições de existência" (ROCHA; MATOS; SALVO e SOUTO, 2010).

Segundo Moraes (2015) pode-se entender o materialismo cultural como herdeiro do materialismo dialético, constituindo-se como um método de análise para as pesquisas sob o amparo dos Estudos Culturais. Moraes (2015, p. 1[grifos da autora]) ressalta que:

Trata-se, agora, de propor um paradigma analítico, que se alia ao protocolo metodológico indicado nos textos que defendem o materialismo cultural como método próprio dos EC, trazendo, para isso, a ideia de que é possível reconhecê-lo como um método de abordagem; ao passo que a análise cultural se constitui, então, em método de procedimento ou método analítico.

Para Wilhiams (2003 [1961], p. 56) é possível definir a teoria da cultura como “o estudo das relações entre os elementos de todo o modo de vida" ocupando-se de uma forma particular de análise, a qual abrange o contexto sócio-histórico e possibilita construir respostas. Assim o autor salienta que:

A análise da cultura tem o intento de descobrir a natureza da organização que constitui o complexo dessas relações. A análise de obras ou instituições específicas é, neste contexto, a análise de seu tipo essencial de organização, as relações que umas ou outras encarnam como partes da organização em seu conjunto. Nela, a palavra-chave é "padrão": qualquer análise cultural útil se inicia com o descobrimento de um tipo característico de padrões, e a análise cultural geral se ocupa das relações entre eles, que às vezes revelam identidades e correspondências inesperadas entre atividades até então consideradas em separado, e em outras ocasiões mostram descontinuidades imprevistas (ibdem, p.56).

Neste viés, buscamos por meio dessa ferramenta metodológica da análise cultural desconstruir todo e qualquer processo de naturalização presente no espaço escolar e nos artefatos culturais analisados em relação as discussões sobre diversidade sexual e de gênero. Assim, tomamos o educativo em uma dimensão para além da sala de aula, das práticas e das instituições de escolarização, ressaltando tais discussões, a fim de problematizar "o modo como elas se constroem discursivamente na cultura, produzindo significados que atuam no estabelecimento de subjetividades e de configurações sociais” (WORTMANN, 2007, p. 78). Segundo Trindade (2007),

A análise cultural trabalha sempre com uma pluralidade de significações de uma época para a outra e em uma mesma época, visando mostrar como ocorreu a invenção de determinadas verdades, os deslocamentos por que passaram, as disputas que enfrentaram nos campos dos conhecimentos científico, político, social e cultural (p. 42). 
Nas contribuições de Raymond Wilhians (1958), a concepção de cultura passa de um grupo restrito de pessoas para corresponder ao modo de vida global, nessa transformação a cultura de massa que abrange os livros, rádio, a tv, mídia em geral privilegiam a análise desses artefatos a partir de suas pedagogias que nos interpelam e nos constituem culturalmente. Nessa perspectiva, Nelson; Treichler e Grossberg (1995) destacam que essa virada na cultura permitiu ao campo dos Estudos Culturais alargar suas possibilidades de pesquisa, tendo como ênfase,

Gênero e sexualidade, nacionalidade e identidade nacional, colonialismo e pós-colonialismo, raça e etnia, cultura popular e seus públicos, ciência e ecologia, política e identidade, pedagogia, política da estética, instituições culturais, política da disciplinariedade, discurso e textualidade e história e cultura global numa era pós-moderna (ibdem, p. 8).

No campo dos Estudos Culturais, o currículo também é empreendido como um artefato cultural composto por um sistema de significação em que a educação e a cultura estão presentes nos processos de transformação da identidade e da subjetividade. Neste aspecto, torna-se relevante analisar nessa perspectiva os artefatos culturais e suas contribuições para a educação, pois através de suas pedagogias e dos temas que perpassam pelos currículos a "cultura em geral é vista como uma pedagogia, a pedagogia é vista como uma forma cultural, onde o cultural torna-se pedagógico e o pedagógico torna-se cultural”. (SILVA, 2013, p. 139).

\section{Permitindo continuar a reflexão}

O investimento desta pesquisa sobre o PNAIC teve como intencionalidade apresentar uma possibilidade de discutir essa política pública enquanto uma possível estratégia para a promoção de uma educação para sexualidade, a partir da proposta e dos materiais oferecidos pelo Programa. A partir das análises dos livros que compõem o Acervo Complementar foi possível refletir sobre outras formas de ser menino e menina, outras maneiras de expressar sua sexualidade, viver e (re)contruir suas identidades. Os livros selecionados expressam a diversidade sexual e de gênero de forma com que as verdades estabelecidas pela sociedade sejam discutidas e repensadas, possibilitando as/aos professoras/es dialogar e discutir, sobre outras formas de perceber as identidades sexuais e de gêneros problematizando, contudo, o que se instaura como norma e como verdade imutável.

Contudo, pensamos que a análise deste Programa e de seus artefatos, possa vir a auxiliar futuramente na prática de uma educação para a sexualidade. No sentido amplo de questionar, refletir, inquietar, desacomodar, questionar, discutir, pensar e problematizar sobre as verdades estabelecidas acerca dos gêneros e das sexualidades. Entendendo que a parir 
destes livros outra forma de diálogo pode ser pensada, instigando formas imaginativas de discutir sobre a produção de subjetividades dos sujeitos envolvidos nas histórias.

Os temas de diversidade sexual e de gênero e a promoção da uma educação para a sexualidade são assuntos que devem estar dentro de todas as agendas e políticas que envolvam a educação, assim como na formação continuada para professoras/es.

Os livros apresentam possibilidades de repensar essas verdades já estabelecidas, no momento em que a/o professora/o problematiza o que está sendo representado nas histórias,

as crianças tendem a representar em suas brincadeiras as identidades de gênero consideradas como "normais" em nossa sociedade. Neste sentido, justificam-se as brincadeiras agitadas e agressivas dos meninos, e tranquilas e passivas das meninas, com conformidade com as identidades atribuídas a ambos os gêneros (PIRES, 2008, p. 57 [Grifos da autora]).

O que requer pensar a partir dessa dissertação, é justamente isso, o que está representado nos livros, que vêm caracterizando o feminino e masculino, e o que eles nos propõe pensar a partir disso. Para tanto, assumimos pensar e entender o PNAIC, enquanto uma estratégia biopolítica e de controle, como forma de governamento, problematizando este espaço, como um espaço de rupturas, sobre o que se pode falar, o que é falado e o que ainda não é permitido ser falado na escola acerca das sexualidades.

As técnicas que se instauram na escola, também disciplinam as/os professoras/es sobre o como se falar dessas temáticas. Tornar a escola um espaço potente para uma educação para a sexualidade é um caminho longo, o qual é evidente que se precise ter diferentes estratégias para sua efetivação. Como ressaltamos nesta pesquisa, um desses caminhos pode ser o uso das obras do Acervo Complementar para promover tais discussões.

Contudo, é necessário destacar que este estudo e pesquisa nos suscitou entender e perceber, que "trabalhar com Foucault é sempre trabalhar na transversalidade, isto é, trabalhar atravessadamente, obliquamente, transversalmente, cruzadamente" (VEIGA-NETO, 2015, p. 50). Entendemos que é preciso ir ao lado contrário do que está sendo posto e estabelecido como único, como verdade ou como norma, é preciso ir contra a corrente, ir contra os modos de pensar que imperam em nossa sociedade e que instauram padrões, sobre o que se pode pensar, falar e ser. O que pensamos nessa escrita foi exatamente isso, o que ainda falta fazer e pensar sobre as infâncias, os gêneros e as sexualidades, pensando em novas estratégias de uma educação para a sexualidade, que possam a vir auxiliar no trabalho pedagógico dentro do espaço escolar. 


\section{REFERÊNCIAS}

ABRAMOVICH. Fanny. Literatura Infantil: gostosuras e bobices / Fanny Abramovich. São Paulo: Scipione, 2009. (Coleção Pensamento e ação na sala de aula).

ARIÉS, P. História social da criança e da família. Trad Dora Flaksman. 2. Ed. Rio de Janeiro: Livros Técnicos e Científicos, 1981.

BRASIL, Ministério da Educação e do Desporto. Secretaria de Educação Fundamental. Referencial Curricular Nacional para a Educação Infantill Ministério da Educação e do Desporto. Secretaria de Educação Fundamental. - Brasília: MEC/SEF. 1998. 3v.: il.

BRASIL, Secretaria de Educação Básica. Parâmetros Curriculares Nacionais. $1^{a}$ a $4^{a}$ série. Brasília: MEC, 1997. 142p.

BRASIL, Secretaria de Educação Básica. Diretoria de Apoio à Gestão Educacional. Pacto Nacional Pela Alfabetização na Idade Certa: formação de professor no pacto nacional pela alfabetização na idade certal Ministério da Educação, Secretaria de Educação Básica, Diretoria de Apoio à Gestão Educacional. - Brasília: MEC, SEB, 2012. 39 p.

BRASIL, Secretaria de Educação Básica. Diretoria de Apoio à Gestão Educacional. Pacto nacional pela alfabetização na idade certa : currículo na alfabetização : concepções $e$ princípios : ano 1 : unidade 1 / Ministério da Educação, Secretaria de Educação Básica, Diretoria de Apoio à Gestão Educacional. -- Brasília : MEC, SEB, 2012. 57 p.

BRASIL, Secretaria da Educação Básica. Acervos Complementares: Alfabetização $e$ Letramento nas diferentes áreas do conhecimento/ Ministério da Educação, Secretaria de Educação Básica. - Brasília: A Secretaria, 2012. 140 p. : il.

BRASIL, Ensino fundamental de nove anos: orientações para a inclusão da criança de seis anos de idade / organização Jeanete Beauchamp, Sandra Denise Pagel, Aricélia Ribeiro do Nascimento. - Brasília: Ministério da Educação, Secretaria de Educação Básica, 2007.135 p. : il.

BUJES, Maria Isabel Edelweiss. Infância e Maquinarias/ Maria Isabel Edelweiss Bujes. Rio de Janeiro: DP\&A, 2002.

CAMARGO, Ana Maria Faccioli de. Sexualidad (s) e infância (s): a sexualidade como um tema transversal/ Ana Maria Faccioli de Camargo, Claudia Ribeiro; coordenação Ulisses F. Araújo. - São Paulo: Moderna; Campinas, SP: Editora da Universidade de Campinas, 1999. (Educação em pauta: Temas Transversais).

ESCOSTEGUY, Ana Carolina D. Cartografias dos Estudos Culturais - Uma versão latino americana. --- Belo Horizonte: Autêntica, 2001.

FELIPE, Jane; GUIZZO, Bianca Salazar; BECK, Dinah Quesada, (organizadoras.)/ Infâncias, gêneros e sexualidade nas tramas da cultura e da educação. - Canoas: Ed. ULBRA, 2013. 
FOUCAULT, Michel. História da sexualidade I: A vontade de saber, tradução de Maria Thereza da Costa Albuquerque e J. A. Guilhon Albuquerque. - $1^{\text {a }}$ ed. São Paulo, Paz e Terra, 2014.

FURLANI, Jimena. O bicho vai pegar! - um olhar pós-estruturalista à educação sexual a partir de livros paradidáticos infantis. Tese de doutorado - Programa de pós-graduação em educação/ Universidade Federal do Rio Grande do Sul - UFRGS.

2005 .

GIROUX, Henry A. Atos impuros: a prática política dos estudos culturais/ Henry A. Giroux; trad. Ronald Cataldo Costa. - Porto Alegre: Artmed, 2003.

GIROUX, Henry A. Memória e pedagogia no maravilhoso mundo da Disney. SILVA, Tomas Tadeu da. Alienígenas na sala de aula: uma introdução aos estudos culturais em educação. Petrópolis: Editora Vozes, 2005.

GOUVÊA, M. C, Soares de. Imagem do negro na literatura infantil brasileira: análise historiográfica. Educação e Pesquisa, São Paulo, volume 31, n. 1 pp. 79-91, jan-abr/2005. Acessado em 20/8/2014. Disponível em: http://www.scielo.br/pdf/ep/v31n1/a06v31n1

GUIMARÃES, Isaura. Educação Sexual na Escola: mito e realidade/ Isaura Guimarães Campinas, SP: Mercado de Letras, 1995.

HALL, Stuart. A identidade cultural na pós-modernidade/ Stuart Hall; tradução Tomaz Tadeu da Silva, Guacira Lopes Louro. Rio de Janeiro. Lamparina. 2014.

HARAWEY, Donna. "Gênero" para um dicionário marxista: a política sexual de uma palavra. Cadernos Pagu, n.22. 2004.

LOURO, Guacira Lopes. O currículo e as diferenças sexuais e de gênero. In: O currículo nos limites do contemporâneo. Marisa Vorraber Costa, org. - Rio de Janeiro: DP\&A, 2005.

LOURO, Guacira Lopes. Gênero, sexualidade e educação: Uma perspectiva pósestruturalista. Petrópolis, Rio de Janeiro: Vozes, 2013a.

LOURO, Guacira Lopes. FELIPE, Jane. GOELLNER, Silvia Vilodre. (Orgs.) Corpo, gênero e sexualidade: um debate contemporâneo na educação. 9, ed. Petrópolis, RJ: Vozes, 2013b.

LOURO, $O$ corpo educado: pedagogias da sexualidadel Guacira Lopes Louro (organizadora); Tradução dos artigos: Tomaz Tadeu da Silva - 3.ed. - Belo Horizonte: Autêntica Editora, 2013c.

LUDKE, M. e ANDRÉ, M. E. D. A., Pesquisa em Educação: Abordagens qualitativas. São Paulo. E.P.U., 1986.

MAIO, Eliane Rosa. O nome da coisa/ Eliane Rosa Maio. - Maringá: UNICORPORE, 2011.

MATTELART, Armand. Introdução aos Estudos Culturais/ Armand Mattelart, Érik Neveu/ [trad.] Marcos Marcionilo. - São Paulo: Parábola Editorial, 2004. 
POSTMAN, Neil. O Desaparecimento da Infância. Tradução: Suzana Menescal de A. Carvalho e José Laurenio de Melo. Rio de Janeiro: Grafhia Editorial, 1999.

RIBEIRO, Claudia Maria. Gênero e Sexualidade no cotidiano de processos educativos: "Apesar de tanta sombra, apesar de tanto medo". In: Gênero, direitos e diversidade sexual: trajetórias escolares/ organizadoras Eliane Rose Maio, Crishna Mirella de Andrade Correa. Maringá: Eduem, 2013.

RIBEIRO, Paula Regina Costa; ÁVILA, Dárcia Amaro. Sujeitos, histórias, experiências, trajetórias... A narrativa como metodologia na pesquisa educacional. In: Pesquisas em Educação: experimentando outros modos investigativos. Coleção cadernos Pedagógicos da EaD Volume 18. 2013.

ROSSEAU, Jean-Jacques. Emílio ou da Educação. Tard. Sérgio Milliet. 3. Ed. Rio de Janeiro: Bertrand Brasil, 1995.

SABAT, Ruth. Pedagogia cultural, gênero e sexualidade. Revista Estudos Feministas, ano 9, $2^{\circ}$ semestre de 2001 .

SILVA, Tomaz Tadeu da. Currículo e Identidade Social: Territórios Contestados. In: SILVA, Tomaz Tadeu da. Alienígenas em sala de aula. Uma introdução aos estudos culturais em educação. Petrópolis, RJ: Vozes, 2005.

SILVA, Tomas Tadeu da. A pedagogia como cultura, a cultura como pedagogia. In: SILVA, Tomas Tadeu da. Documentos de Identidade: uma introdução às teorias do currículo. Belo Horizonte: Autêntica, 2013.

TONIETTE, M. Augusto. Um breve olhar histórico sobre a história da homossexualidade. Revista Brasileira de Sexualidade Humana, São Paulo: Iglu. v. 17, n.1, p.42-52, jan./jun. 2006.

TREICHLER, P. A.; GROSSBERG, L.. Estudos culturais: uma introdução. In: SILVA, T. T. (Org.) Alienígenas na sala de aula: uma introdução aos estudos culturais em educação. Petrópolis: Vozes, 1995.

WORTMANN, Maria Lúcia Castanha. Análises Culturais - Um modo de lidar com histórias que interessam à educação. In: Caminhos investigativos II: outros modos de pensar e fazer pesquisa em educação/ Marisa Vorraber Costa (organizadora) - 2. Ed. Rio de Janeiro: Lamparina editora, 2007.

XAVIER FILHA, Constantina . Livros como instrumentos de dispositivos pedagógicos para a educação da infância. In: ANPED - SUL, 2010, Londrina/PR. ANPED-SUL 2010: Formação, ética e políticas: qual pesquisa? qual educação? Londrina, PR: Universidade Estadual de Londrina, 2010.

XAVIER FILHA, Constantina. Gênero, sexualidade e diferença em livros para a infância. In: Educação para a sexualidade/ Ana Cláudia Bortolozzi Maia ... [et al.]; [organizadores:] Joanalira Corpes Magalhães; Paula Regina Costa Ribeiro. - Rio Grande: Ed. Da FURG, 2014. 